\title{
Types, stability, and phenotypic consequences of chromosome rearrangements leading to interstitial telomeric sequences
}

\author{
E Rossi, G Floridia, M Casali, C Danesino, G Chiumello, F Bernardi, I Magnani, \\ L Papi, M Mura, O Zuffardi
}

Biologia Generale e Genetica Medica, Università di Pavia, CP 217, I-27100 Pavia,

Italy.

E Rossi

G Floridia

M Casali

C Danesino

O Zuffardi

\section{Clinica Pediatrica,} Ospedale San

Raffaele, Università di Milano, Milano, Italy. G Chiumello

Laboratorio di Genetica, Policlinico Borgo Roma, Verona, Italy.

F Bernardi

Dipartimento di Biologia e Genetica, Università di Milano, Milano, Italy.

I Magnani

Genetica Medica, Università di Firenze, Italy.

L Papi

Anatomia Patologica, Ospedale Niguarda Ca Granda, Milano, Italy. M Mura

Correspondence to Dr Zuffardi.

Received 19 May 1993. Accepted 22 June 1993.

\begin{abstract}
Using in situ hybridisation, we identified interstitial telomeric sequences in seven chromosomal translocations present in normal and in syndromic subjects. Telomeric sequences were also found at the centromeric ends of a $4 p$ and a $4 q$ caused by centric fission of one chromosome 4 . We found that rearrangements leading to interstitial telomeric sequences were of three types: (1) termino-terminal rearrangements with fusion of the telomeres of two chromosomes, of which we report one case; (2) rearrangements in which an acentric fragment of one chromosome fuses to the telomere of another chromosome. We describe four cases of Prader-Willi syndrome with the 15q1qter transposed to the telomeric repeats of different recipient chromosomes; (3) telomere-centromere rearrangements in which telomeric sequences of one chromosome fuse with the centromere of another chromosome. We describe two examples of these rearrangements in which not only telomeric sequences but also remnants of alphoid sequences were found at the fusion point.

Instability at the fusion point of the derivative chromosome was found in the Prader-Willi translocations but we were unable to correlate this instability with culture conditions. The two subjects with the termino-terminal rearrangement and the centric fission respectively have normal phenotypes. The two patients with telomere-centromere fusions were unbalanced for the short arm of an acrocentric chromosome and had failure to thrive; one of them also had dysmorphic facies. We postulate that these pheno-
\end{abstract}

types could be the result of uniparental disomy.

(f Med Genet 1993;30:926-31)

Linear chromosomes contain two telomeres, one at each end of the molecule, consisting of short, tandemly repeated DNA sequences which are loosely conserved in eukaryotes. ${ }^{1}$ There are, however, several examples in vertebrates of non-telomeric sites of the telomeric sequences. In some species, including our own, the interstitial location of telomeric sequences is a fixed characteristic of some chromosome pairs, ${ }^{2-5}$ in others it is the consequence of rearrangements found in exceptional cases. ${ }^{6}$ In at least one case, that of human chromosome 2 , the interstitial telomere sequences map in the same region as a folate sensitive fragile site. ${ }^{7}$ This coincidence indicates that interstitial telomeric sequences may cause fragility, in other words that some fragile sites are such because they are constituted by telomeric sequences. We report seven examples of human constitutional chromosome abnormalities involving the presence of interstitial telomeric sequences and associated with different phenotypes. In some of these cases the sites of the interstitial telomere coincide with a fragile site. We also investigated a case of familial centric fission to find out whether new telomere sequences were present at the two broken ends of the fission chromosome.

\section{Case reports and methods}

The major symptoms and cytogenetic data of the subjects are shown in table 1 . Cell lines from all cases but case 5 are available. Five of the cases have been described previously, as indicated in table 1 .

Studies on fragile site expression were

Table 1 Karyotypes and phenotypes of the eight subjects.

\begin{tabular}{|c|c|c|}
\hline $\begin{array}{l}\text { Case no } \\
\text { (age at last } \\
\text { observation, y) }\end{array}$ & Karyotype & Main symptoms \\
\hline $1(1)$ & $45, X X$,ter rea $(17 ; 22)(p ; q)$ de novo & \multirow{2}{*}{$\begin{array}{l}\text { Normal phenotype, normal psychomotor development. Chromosome abnormality } \\
\text { detected when her mother requested amniocentesis for advanced age ( } 42 \text { years) } \\
\text { Neonatal hypotonia, obesity, mental retardation. See Rivera et al, }{ }^{8} \text { case } 2 \\
\text { Neonatal hypotonia, obesity, severe mental retardation. See Rivera et al } l^{8} \text { case } 1\end{array}$} \\
\hline $\begin{array}{l}2(21) \\
3(11)\end{array}$ & $\begin{array}{l}45, \mathrm{XX},-5,-15,+\operatorname{der}(5) \mathrm{t}(5 ; 15)(\mathrm{qter} ; \mathrm{q} 13) \text { de novo } \\
45, \mathrm{XX},-15,-18,+\operatorname{der}(18) \mathrm{t}(15 ; 18)(\mathrm{q} 13 ; \mathrm{qter}) / \\
45, \mathrm{X},-\mathrm{X},-15,+\operatorname{der}(\mathrm{X}) \mathrm{t}(\mathrm{X} ; 15)(\mathrm{qter} ; \mathrm{q} 13) \text { de novo }\end{array}$ & \\
\hline $\begin{array}{l}4(12) \\
5(27)\end{array}$ & $\begin{array}{l}45, \mathrm{XX},-12,-15,+\operatorname{der}(12) \mathrm{t}(12 ; 15)(\mathrm{qter} ; \mathrm{q} 11.1) \text { de novo } \\
45, \mathrm{XY},-9,-15,+\operatorname{der}(9) \mathrm{t}(9 ; 15)(\mathrm{qter} ; \mathrm{q} 11.1) \text { de novo }\end{array}$ & \multirow{4}{*}{$\begin{array}{l}\text { Neonatal hypotonia, obesity, mental retardation } \\
\text { Neonatal hypotonia, mild mental retardation, slight obesity, cryptorchidism. See } \\
\text { Fraccaro et al } \\
\text { Dysmorphic facial features, failure to thrive, slight mental retardation. See Di Lernia } \\
\text { et al } l^{10} \text { and Magnani } \text { et } a l^{11} \\
\text { Failure to thrive. Very thin build }\end{array}$} \\
\hline $6(12)$ & $45, \mathrm{XX},-2,-22,+\operatorname{der}(2) \mathrm{t}(2 ; 22)($ qter;cen $)$ de novo & \\
\hline $7(5)$ & $\begin{array}{l}45, \mathrm{XY},-5,-13,+\operatorname{der}(5) \mathrm{t}(5 ; 13)(\mathrm{pter} ; \mathrm{cen}) / 46, \mathrm{XY} \\
-5,-13,+\operatorname{der}(5) \mathrm{t}(5 ; 13)(\text { pter;cen }),+\mathrm{i}(13 \mathrm{p}) \mathrm{de} \text { novo }\end{array}$ & \\
\hline $8(52)$ & $47, \mathrm{XX},-4,+4 \mathrm{p},+4 \mathrm{q}$ & \\
\hline
\end{tabular}


Table 2 Chromosome fragility at the fusion points of the rearranged chromosomes from cases 1 to 7 .

\begin{tabular}{lcccccc}
\hline & RPMI & $\begin{array}{c}\text { RPMI } \\
\text {-FA }\end{array}$ & $\begin{array}{c}\text { RPMI } \\
+ \text { DA }\end{array}$ & $\begin{array}{c}\text { RPMI } \\
+ \text { Aph }\end{array}$ & $\begin{array}{c}\text { RPMI } \\
+ \text { BrdU }\end{array}$ & Totals \\
\hline Case 1 & $0 / 72$ & $0 / 202$ & $0 / 71$ & $0 / 126$ & - & $0 / 471$ \\
Case 2 & $0 / 100$ & $0 / 100$ & $1 / 50^{*}$ & - & - & $1 / 250$ \\
Case 3 & $0 / 100$ & $1 / 79+$ & $0 / 100$ & - & - & $1 / 279$ \\
Case 4 & $0 / 161$ & - & $2 / 100$ & $1 / 50$ & - & $3 / 311$ \\
Case 5 & $2 / 60_{+}^{+}$ & $1 / 106_{+}^{+}$ & $2 / 60$ & $1 / 98 \S$ & $1 / 102_{+}^{+}$ & $7 / 426$ \\
Case 6 & $0 / 100$ & $0 / 100^{2}$ & - & - & - & $0 / 200$ \\
Case 7 & $0 / 100$ & - & - & - & - & $0 / 100$ \\
\hline
\end{tabular}

* Chromosome break (fig 1D).

+ Deletion of 15q1-qter both from the $\operatorname{der}(18)$ and from the $\operatorname{der}(\mathrm{X})$ (fig 1E).

+ Chromatid breaks (fig $1 \mathrm{~A}, \mathrm{~B}$ ).

$\S$ Transposition of $15 \mathrm{q} 1$-qter to $6 \mathrm{q}(46, \mathrm{XY},-6,+\operatorname{der}(6)$, $t(6 ; 15)($ qter-q11.1))

$\mathrm{FA}=$ folic acid, $\mathrm{DA}=$ distamycin $\mathrm{A}, \mathrm{Aph}=$ aphidicolin, $\mathrm{BrdU}$ $=$ bromodeoxyuridine.
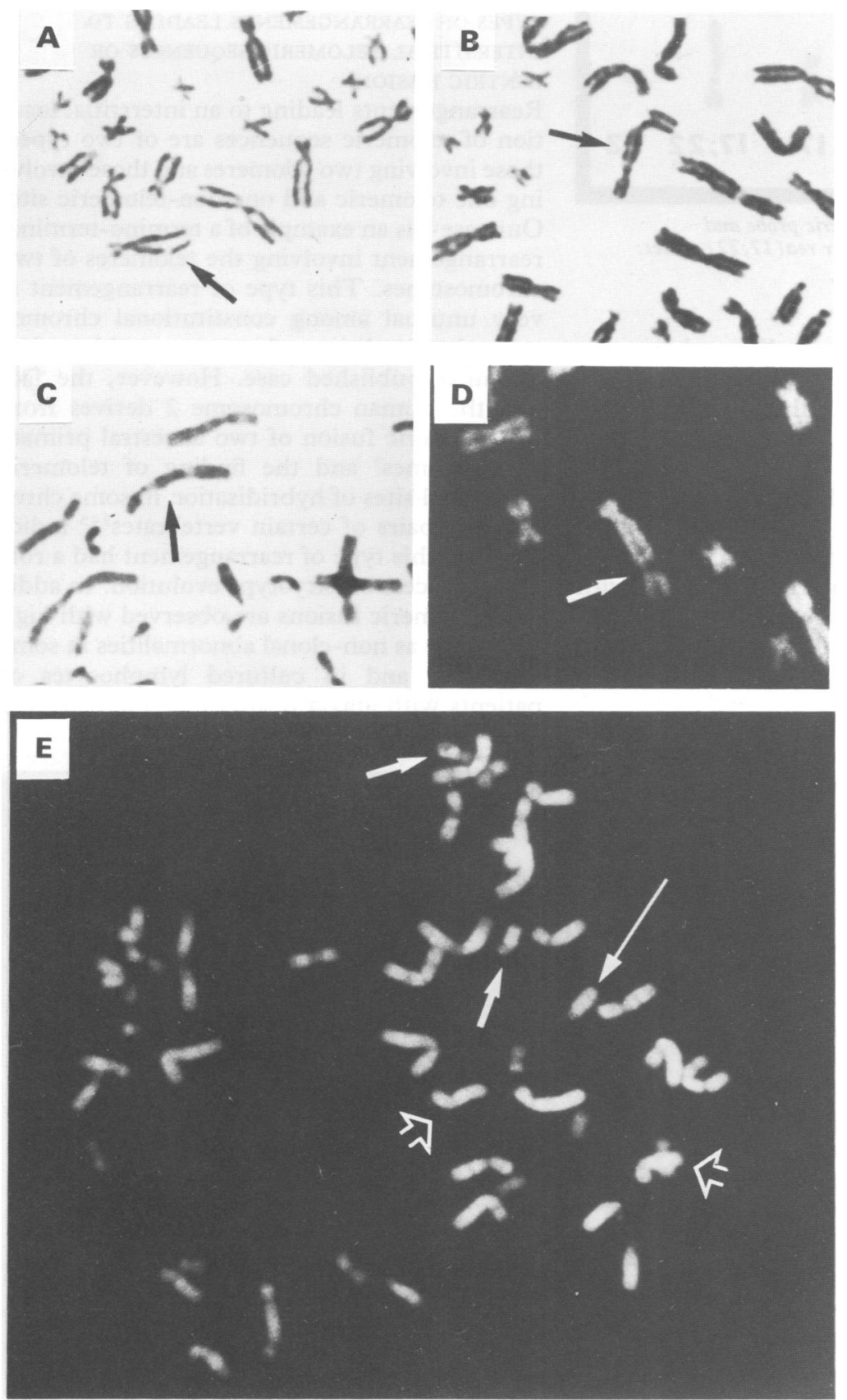

Figure 1 Partial metaphases from case 5 showing chromatid breaks $(A, B)$ and chromosome gap (C) at the fusion point of the der(9). (D) Partial metaphase from case 2 showing break at the fusion point of the $\operatorname{der}(5)$. (E) Metaphases from case 3 showing deletion of 15q1-qter both from the der (18) and from the der $(X)$. Long arrow indicates the normal chromosome 15. Open arrows and short arrows indicate the two $X$ chromosomes and the two chromosomes 18 respectively. undertaken in cultured lymphocytes from all cases but case 7 . Standard cultures were established in RPMI-1640 medium supplemented with $10 \%$ FBS and $0.8 \%$ L-glutamine and were processed at 72 hours. For the expression of folate sensitive fragile sites, cultures from cases 1, 2, 3, 5, and 6 were established in modified RPMI-1640 without folic acid (FA) (Irvine Scientific), supplemented with $10 \%$ FBS, and were processed at 96 hours. Induction of distamycin A (DA) fragile sites was studied in cases 1 to 5 with the addition of DA $(100 \mu \mathrm{g} / \mathrm{ml})$ for the last 48 hours. ${ }^{13}$ Cultures were processed at 72 hours. BrdU inducible fragile sites were studied in case 5 . BrdU $(40 \mathrm{mg} / \mathrm{l})$ was added six hours before harvest at 72 hours. ${ }^{14}$ For the expression of aphidicolin inducible fragile sites, blood cultures from cases 1,4 , and 5 were supplemented with $0.2 \mu \mathrm{mol} / 1$ aphidicolin (Aph) after 70 hours of culture and processed at 96 hours. ${ }^{15}$

In situ hybridisation was performed in all cases with the biotinylated telomeric sequences (TTAGGG)n (P5097-B.5, ONCOR). Hybridisation and posthybridisation washes were performed according to the manufacturer's instructions. Detection was done with the ONCOR detection kit with three amplification steps. Chromosomes were counterstained with propidium iodide $(1 \mu \mathrm{g} / \mathrm{ml})$ and banded with DAPI $(0.5 \mu \mathrm{g} / \mathrm{ml})$. In some cases (cases 6 to 8 ) in situ hybridisation was also performed with the alphoid probe $\mathrm{p} 82 \mathrm{H}$ to test for the presence of alphoid sequences at the breakpoint of the rearrangements. $\mathrm{p} 82 \mathrm{H}$ is specific for chromosome $14^{16}$ so hybridisation and posthybridisation washes were performed in conditions that allowed all alphoid sequences to be detected (hybridisation $37^{\circ} \mathrm{C}$ in $50 \%$ formamide $/ 2 \times$ SSC, posthybridisation washes $30 \%$ formamide $/ 2 \times$ SSC). In cases 6 and $7 \mathrm{p} 82 \mathrm{H}$ was labelled by nick translation with biotin-16-dUTP. Detection was as for the telomeric probe. In case $8, \mathrm{p} 82 \mathrm{H}$ was labelled by nick translation with digoxigenin11-dUTP; detection was with the digoxigenin detection kit according to the manufacturer's instructions (Boehringer Mannheim).

In each case a minimum of 20 metaphases were analysed in each hybridisation experiment.

\section{Results}

The results of chromosome analyses are given in table 1. C banding, performed in all cases, showed the presence of a second, inactive centromere only in case 1 in which the chromosome 22 centromere was consistently inactive. No remnant of $\mathrm{C}$ banding was detected at the fusion point of the rearrangements of cases 6 and 7 although in both cases the chromosome portion transposed to the telomere of the recipient chromosome was broken at the centromere. In case 8 both the centromeres of $4 p$ and 4q were $C$ positive.

Results of chromosome fragility studies at the fusion point of the rearrangements from cases 1 to 7 are given in table 2 . In case 5 , the fusion point of the $\operatorname{der}(9)$ appeared as a gap 


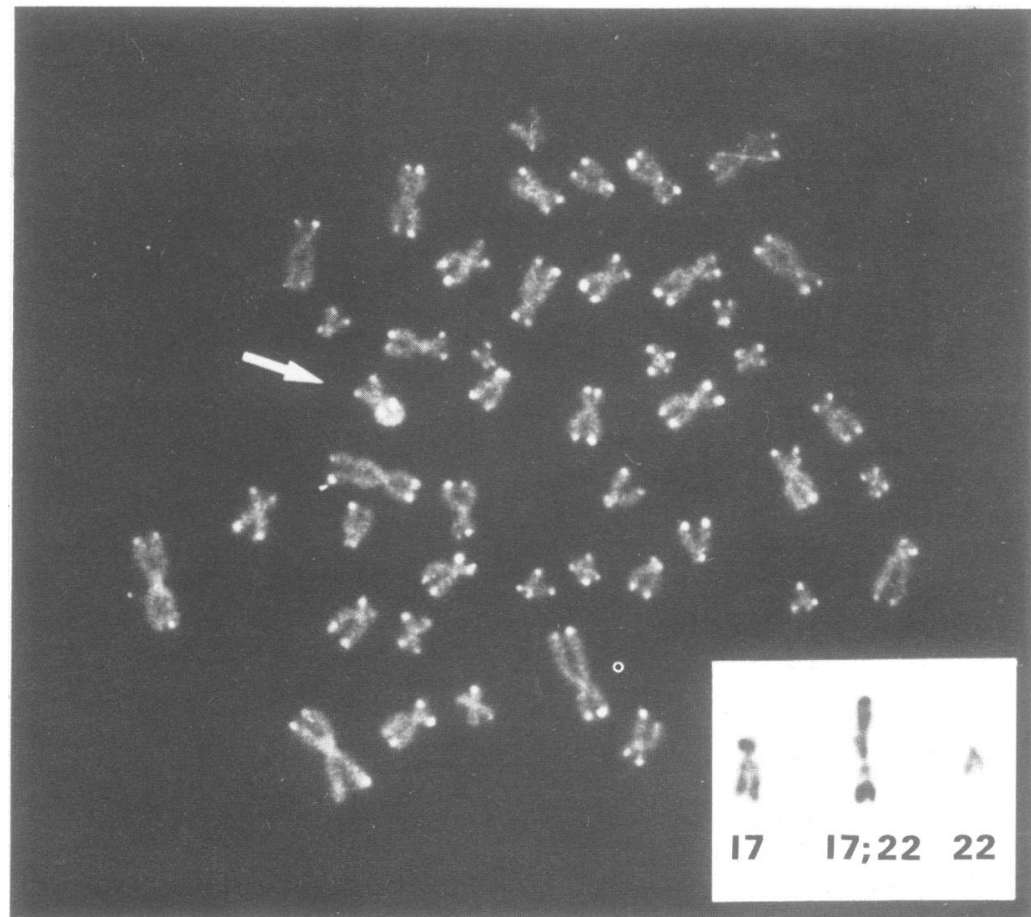

Figure 2 Metaphase from case 1 hybridised with the telomeric probe and counterstained with propidium iodide. Arrow indicates the ter rea $(17 ; 22)$. Inset cutout of chromosomes 17,22 , and the ter rea $(17 ; 22)$.

(fig 1C) in nearly all the cells, and for this reason it was not considered among the fragile sites in table 2 . The size of the gap excluded its origin by fusion of the two $\mathrm{G}$ negative bands $9 \mathrm{q} 34$ and $15 \mathrm{q} 11.1$ (fig 1C). In this case, in a single cell from the aphidicolin treated cultures, we also found a $\operatorname{der}(6)$ instead of the $\operatorname{der}(9)$ and this was entered in table 2 as a fragile site. Conversely, in case 3, mitoses with the $\operatorname{der}(\mathrm{X})$ instead of the $\operatorname{der}(18)$ were not entered in table 2 since they were considered constitutional as they were also found in fibroblasts. ${ }^{8}$
FISH analysis showed that all the rearrangements from cases 1 to 7 contained telomeric sequences at the fusion point (figs 2,3 , 4). In case 8 telomeric sequences were also found at the centromeric ends of $4 p$ and $4 q$ (fig 5). In cases 6 and 7, FISH analysis with p82h showed hybridisation signals at the fusion point of both the $\operatorname{der}(2)$ and the $\operatorname{der}(5)$. However, these signals were much smaller (fig 4) than those found at the primary constrictions of the other chromosomes, and in case 7 they were detectable in only four of 20 metaphases. Conversely in case 8 hybridisation signals with $\mathrm{p} 82 \mathrm{H}$ at $4 \mathrm{p}$ and $4 \mathrm{q}$ were very evident.

\section{Discussion}

TYPES OF REARRANGEMENTS LEADING TO INTERSTITIAL TELOMERIC SEQUENCES OR CENTRIC FISSION

Rearrangements leading to an interstitial location of telomeric sequences are of two types: those involving two telomeres and those involving one telomeric and one non-telomeric site. Our case 1 is an example of a termino-terminal rearrangement involving the telomeres of two chromosomes. This type of rearrangement is very unusual among constitutional chromosome abnormalities and we were unable to find a similar published case. However, the fact that the human chromosome 2 derives from the telomeric fusion of two ancestral primate chromosomes ${ }^{3}$ and the finding of telomeric interstitial sites of hybridisation in some chromosome pairs of certain vertebrates ${ }^{245}$ indicates that this type of rearrangement had a role in the process of karyotype evolution. In addition, telomeric fusions are observed with high frequency as non-clonal abnormalities in some tumours ${ }^{17}$ and in cultured lymphocytes of patients with ataxia telangiectasia and related

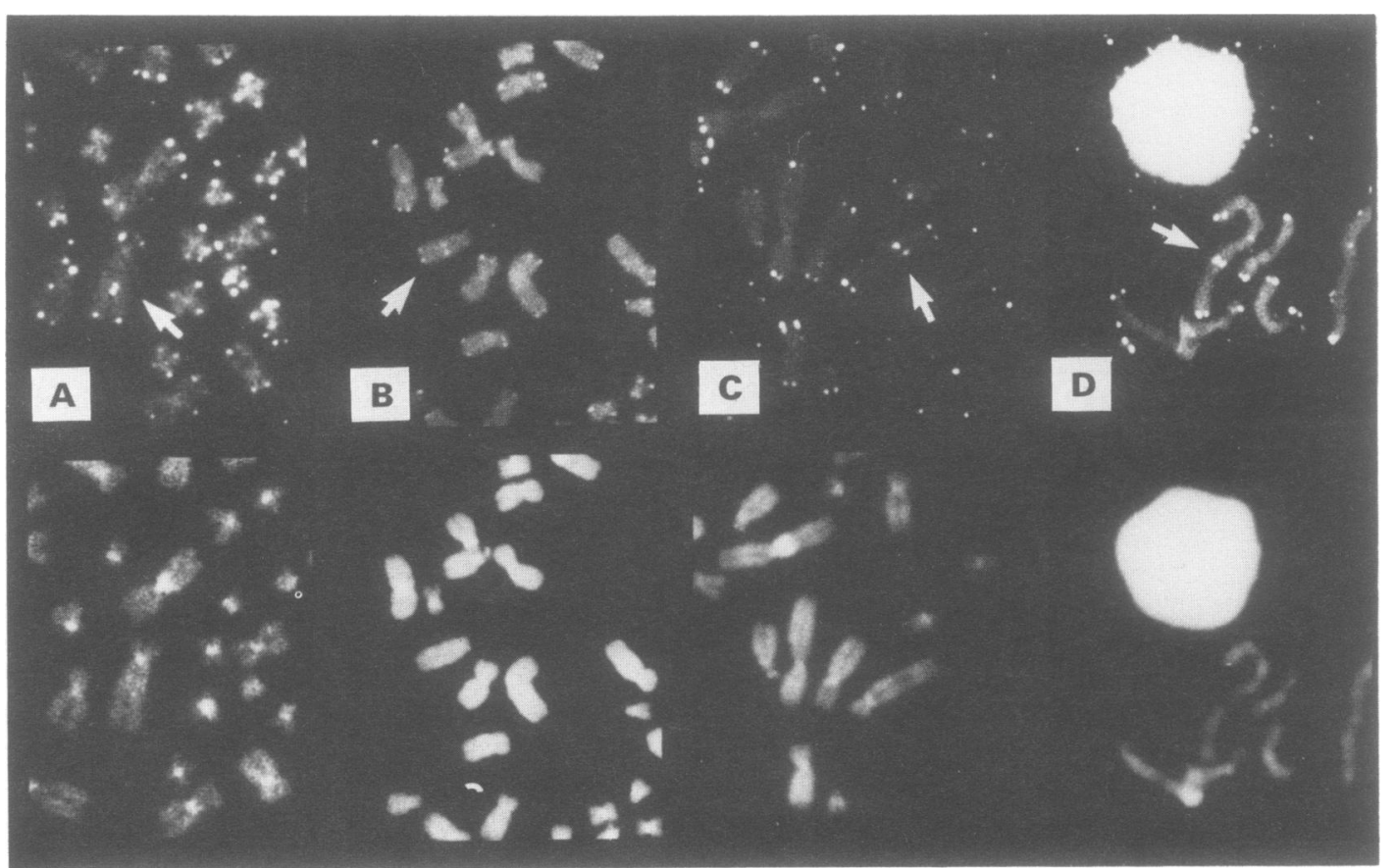

Figure 3 Partial metaphases from cases $2(A), 3(B), 4(C)$, and $5(D)$ after hybridisation with the telomeric probes (top) and after staining with DAPI (bottom). 


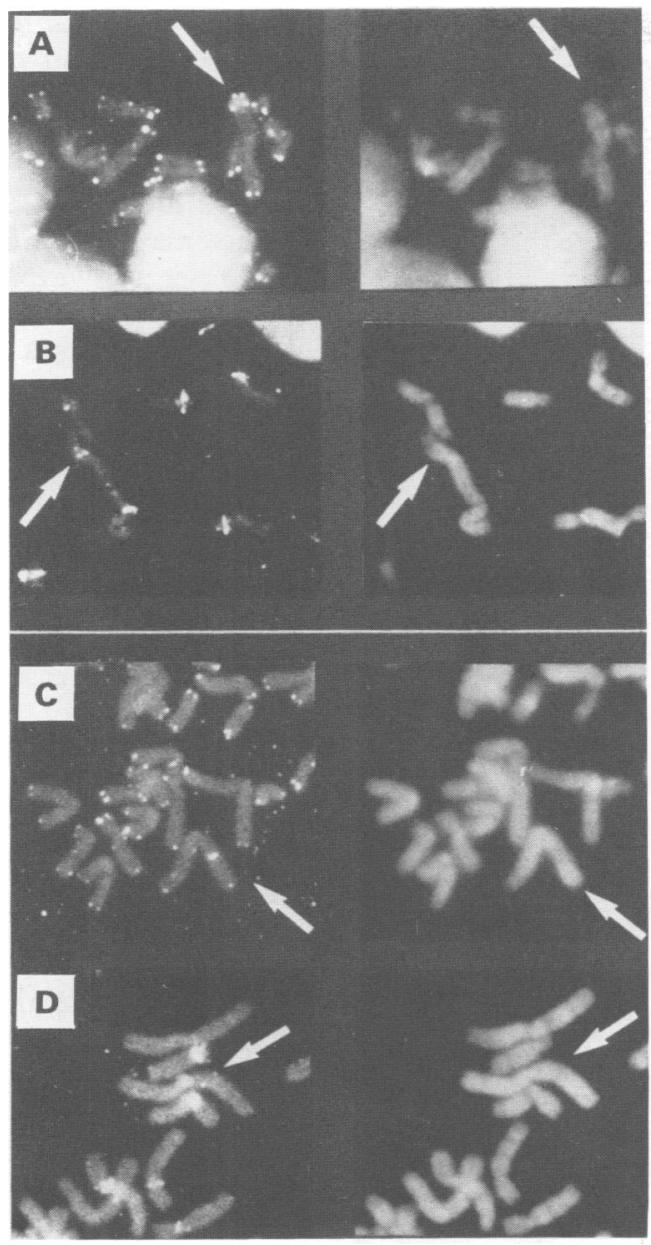

Figure 4 Partial metaphases from case $6(A, B)$ and 7 $(C, D)$ hybridised with the telomeric probe $(A, C)$ and with $p 82 H(B, D)$. The same metaphases stained with $D A P I$ are shown on the right. Arrows indicate the derivative chromosomes.

syndromes. ${ }^{18}$ Thus it seems likely that some genetic conditions may predispose to telomere fusion. The same holds true for ring chromosomes that have been found, as recurrent events, in various haematological and solid tumours. ${ }^{19}$ Some of the ring chromosomes, either constitutional or acquired, appear to originate through telomere-telomere fusions. This mechanism was shown in three cases of constitutional ring chromosome, in which it was possible to detect not only the telomeric sequences but also the telomere associated ones. ${ }^{20}$ Thus it seems that termino-terminal rearrangements occur not only between the telomeres of two chromosomes but also between the distal ends of the same chromosome. Cases 2, 3, 4, 5, 6, and 7 are all examples of rearrangements involving one telomeric and one non-telomeric site. The first four cases are patients with the Prader-Willi syndrome. In these cases the rearrangements involve most of the chromosome 15 long arm that is transposed to the very terminal region of a recipient chromosome. The presence of telomeric sequences at the fusion point of similar PraderWilli translocations was suspected ${ }^{8}$ for several reasons: (1) 15q1-qter is always transposed to the distal portion of the recipient chromosome and in some cases it jumps from one chromosome to another in different cells of the same subject, and (2) the reciprocal product of the translocation, when present, is not the expected 15 pter-q1 but an inv $\operatorname{dup}(15 q 1)$. In situ hybridisation with telomere sequences showed that in cases $2,3,4$, and 5 the recipient chromosome maintained its telomere. The same finding has been reported in three cases of Prader-Willi translocations. ${ }^{621}$ Thus it seems likely that in most Prader-Willi translocations, 15q1-qter is transposed to the telomeric sequences of the recipient chromosome. Since it is unlikely that the entire 1 to $1.5 \mathrm{Mb}$ Prader-Willi chromosome region (PWCR) has affinity for the telomere, there must be unique or repeated sequences with this characteristic along it. In two translocation patients in whom molecular studies have been done, the chromosome 15 breakpoint is distal to TD189-1 and proximal to IR10-1.22 Thus sequence(s) prone to attach to telomeres could be present inside this region. Sequences with affinity for the telomeres are not exclusive to the PWCR as shown by similar rearrangements involving other chromosomes. ${ }^{6}$

The rearrangements found in cases 6 and 7 are also instances of fusion between telomeric and non-telomeric sequences but in these cases the non-telomeric sequences are part of the centromere as indicated by the finding of remnants of alphoid sequences at the fusion point of both the $\operatorname{der}(2)$ and the $\operatorname{der}(5)$. In case 7 we are confident that the breakpoint of chromosome 13 is at the centromere, since its reciprocal product is an $\mathrm{i}(13 \mathrm{p})$. In case 6 , a $2 ; 22$ translocation, the absence of an $\mathrm{i}(22 \mathrm{p})$ does not exclude a breakpoint in the chromosome 22 short arm, but the presence at the fusion point of the $\operatorname{der}(2)$ of a very small domain of alphoid DNA and its banding pattern do indeed suggest that it derives from telomere-centromere fusion. The existence of this type of rearrangement, that is, breakage of the centromere of one chromosome, transposition of one of its arm to the telomere of another chromosome, and duplication of the other arm to form an isochromosome, was postulated by Aurias and Dutrillaux, ${ }^{23}$ who reviewed several cases in which this rearrangement could have happened. Our finding that alphoid and telomere sequences were both present at the fusion point does not in itself indicate that telomere sequences actually stick to the alphoid ones, since centromeres contain several classes of repetitive DNA. ${ }^{24}$

In case 8 a fission of chromosome 4 is present and is found in other members of the family. ${ }^{12}$ As was the case with chromosome 13 in case 7 , in situ hybridisation showed that alphoid sequences were present at both of the broken ends of chromosome 4 . In this case the two portions of chromosome 4 are stable and, unlike those of chromosome 13 in case 7, are neither prone to stick to telomeres of other chromosomes nor to form an isochromosome. The reason for this stability is the presence of telomere sequences at each of the two broken ends. It is not obvious why chromosomes broken at the centromere can alternatively generate a new telomere, stick to telomeres of other chromosomes, or form an isochromo- 


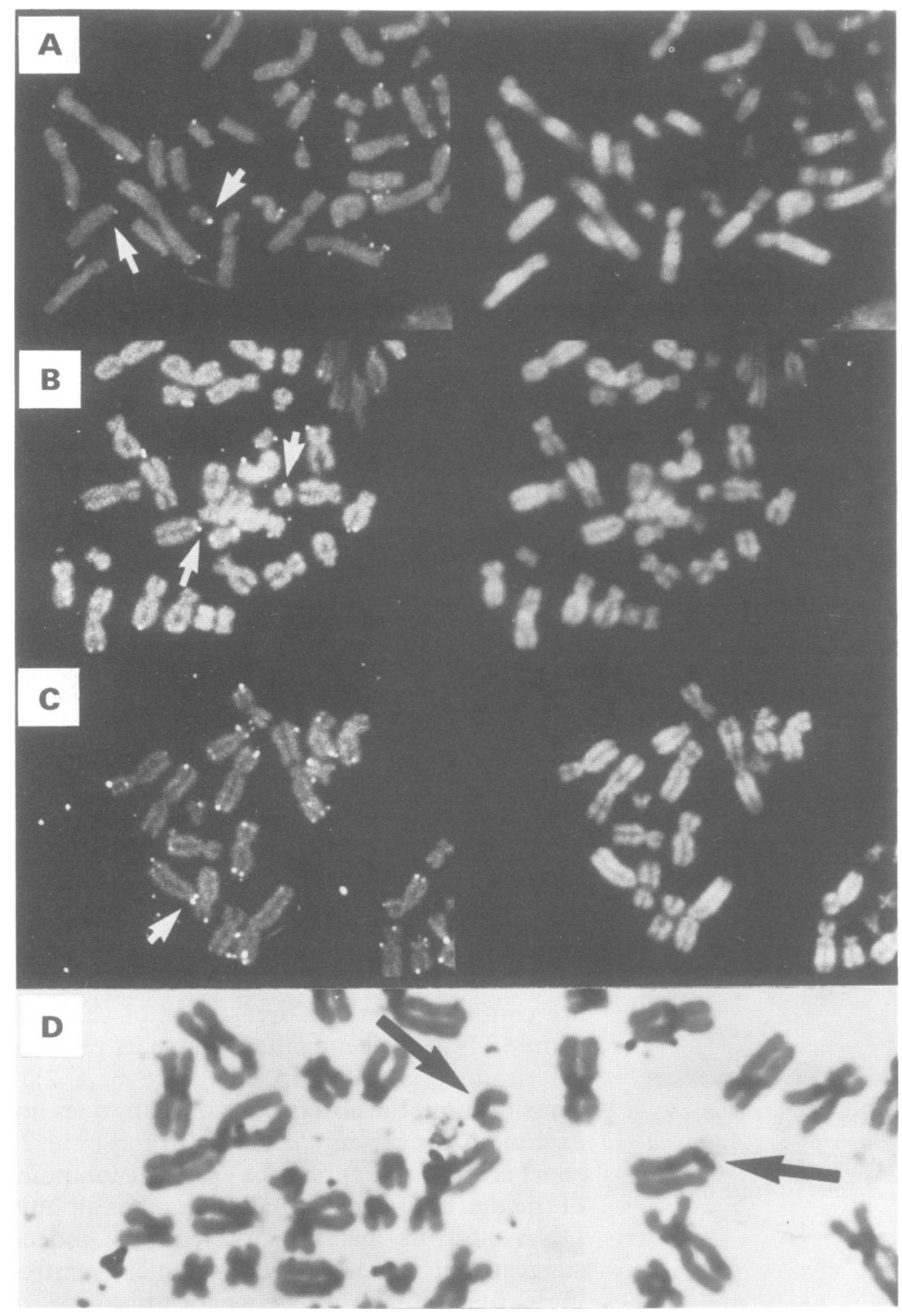

Figure 5 Partial metaphases from case 8 hybridised with the telomeric probe $(A, B, C)$ and with $p 82 H(D)$. Arrows indicate the two derivatives $4 p$ and $4 q$ originating from the centric fission $(A, B, D)$. In $(C)$ only $4 q$ is shown. DAPI staining of metaphases is shown on the right.

some. The only difference we noticed between the two broken chromosomes was in the amount of alphoid DNA, which was minimal in the long arm of chromosome 13 joined to the telomere of $5 p$ and larger in $4 p$ and $4 q$. The finding that broken chromosomes can be stabilised by de novo formation of telomeres is not new. In Tetrahymena it has been shown ${ }^{25}$ that telomerase can add telomeric repeats directly onto the ends of germline fragmented chromosomes that lack any pre-existing telomeric DNA. Similarly, in Ascaris lumbricoides, the newly formed ends of the reduced somatic chromosomes carry new tandem repeats of telomeric sequences. ${ }^{26}$ At least two examples of healing of a truncated chromosome by the addition of telomeric repeats have been reported in humans. ${ }^{2728}$

ARE INTERSTITIAL TELOMERES FRAGILE SITES? There is general agreement that interstitial telomeres can be sites of chromosome fragi- lity. ${ }^{17}$ The evidence that in human chromosome 2 the fusion point of two ancestral chromosomes maps to the same band of the rare folic acid sensitive fragile site fra2B suggests that, similarly to what was found at fraXA, in some subjects the expansion of interstitial telomere repeats may result in a folic acid sensitive fragile site. However, the demonstration that telomeric repeats do coincide with fra2B is still lacking. In our cases 1 to 7 chromosome breaks at the fusion point were seen only in the Prader-Willi translocations (cases 2 to 5), mainly as chromatid breaks (fig 1). From our experiments, chromosome fragility in the four Prader-Willi translocations seems to be independent of the culture conditions. A similar instability was described in another PraderWilli translocation ${ }^{21}$ and in a telomeric translocation $6 ; 19 .^{29}$ In cases 1,6 , and 7 no fragility was found in any of the derivative chromosome although case 1 was extensively investigated in different culture conditions.

In conclusion, interstitial telomeric sequences can be considered in some cases as non-functional elements analogous to the inactivated centromeres. ${ }^{6}$ In other cases, the telomeric sequences seem to maintain some of their function and are prone to breakage. The jumping phenomenon of the Prader-Willi translocations ${ }^{8}$ shows that the internal telomere repeats maintain part of the telomere function of preventing fusion with other chromosomes.

\section{PATIENTS' PHENOTYPE}

The phenotypes of cases 1 to 5 and 8 are as expected. Cases 1 and 8 carry balanced rearrangements and are completely normal, while cases 2 to 5 have the Prader-Willi syndrome. The severity of the condition varies considerably from case 3 with severe obesity and mental retardation to case 4 showing slight obesity and very mild mental retardation. This phenotypic variation could be because of the varying size of the chromosome 15 deletion or differences in the parental origin of the translocation or both. In fact some phenotypic differences were found between Prader-Willi patients with the deletion and those with uniparental maternal disomy. ${ }^{30}$

Cases 6 and 7 have chromosome imbalances involving the short arms of acrocentric chromosomes and should have a normal phenotype. However, both failed to thrive and case 7 also had a dysmorphic face. We cannot exclude the possibility that these abnormalities are the result of an undetected chromosome instability leading to mosaic monosomy for $22 \mathrm{q}$ (case 6 ) and $13 q$ (case 7 ), but they could be the result of uniparental disomy for one of the chromosomes involved in the rearrangements. In fact abnormalities of growth have been reported in several instances of uniparental disomy in $\operatorname{man}^{31-34}$ and mouse. ${ }^{35}$

We thank Professor M Fraccaro for important suggestions and critical reading of the manuscript. This work was supported in part by Associazione Studio Malformazioni, Milano. 
1 Blackburn EH. Structure and function of telomeres. Nature 1991;350:569-73.

2 Meyne J, Baker RJ, Hobart HH, et al. Distribution of nontelomeric sites of the (TTAGGG) telomeric sequences in telomeric sites of the (TTAGGG) telomeric sequences

3 Ijdo JW, Baldini A, Ward DC, Reeders ST, Wells RA. Origin of human chromosome 2: an ancestral telomeretelomere fusion. Proc Natl Acad Sci USA 1991;88:90515.

4 Wiley JE, Meyne J, Little ML, Stout JC. Interstitia hybridization sites of the (TTAGGG) telomeric sequence on the chromosomes of some North American hylid frogs. Cytogenet Cell Genet 1992;61:55-7.

5 Ashley T, Ward DC. A "hot spot" of recombination coincides with an interstitial telomeric sequence in the coincides with an interstitial telomeric sequence in the

6 Murtif Park V, Gustashaw KM, Wathen TM. The presence of interstitial telomeric sequences in constitutional
chromosome abnormalities. Am 7 Hum Genet 1992;50:914-23.

7 Allshire RC, Gosden JR, Cross SH, et al. Telomeric repeat from $\mathrm{T}$ thermophila cross hybridizes with human telomeres. Nature 1988;332:656-9.

8 Rivera H, Zuffardi O, Gargantini L. Nonreciprocal and jumping translocations of $15 \mathrm{ql} \rightarrow \mathrm{qter}$ in Prader-Will syndrome. Am 7 Med Genet 1990;37:311-17.

9 Fraccaro M, Zuffardi O, Buhler E. Deficiencies involving the paracentromeric regions of chromosome 15: PraderWilli or a new syndrome? Klinische Genetik in der Pädiatrie. I. Symposium in Kiel. Herausgegeben von M Tolksdorf und J Spranger. Stuttgart: Georg Thieme Verlag, 1978:33-8.

10 Di Lernia R, Magnani I, Doneda L, Rizzi R, Larizza L. Cytogenetic instability in a family with gastric cance recurrence. Cancer Genet Cytogenet 1987;27:299-310.

11 Magnani I, Larizza L, Doneda L, Weitnauer L, Rizzi R, Di Lernia $R$. Malformation syndrome with $t(2 ; 22)$ in a cancer family with chromosome instability. Cancer Genet Cytogenet 1989;38:223-7.

12 Dallapiccola B, Mastroiacovo P, Gandini E. Clinical case report. Centric fission of chromosome no 4 in the mother of two patients with trisomy 4p. Hum Genet 1976;31:1215.

13 Schmid M, Feichtinger W, Jessberger A, Köhler J, Lange $R$. The fragile site (16)(q22). I. Induction by AT-specific DNA-ligands and population frequency. Hum Genet 1986;74:67-73.

14 Sutherland GR, Parslow MI, Baker E. New classes of common fragile sites induced by 5-azacytidine and bromodeoxyuridine. Hum Genet 1985;69:233-7.

15 Austin MJF, Collins JM, Corey LA, et al. Aphidicolininducible common fragile-site expression: results from a population survey of twins. Am $\mathcal{F}$ Hum Genet 1992;50:76-

16 Waye JS, Mitchell AR, Willard HF. Organization and genomic distribution of ' $82 \mathrm{H}$ ' alpha satellite. DNA evidnce for a low-copy or single-copy alphoid domain located on human chromosome 14. Hum Genet 1988;78:27-32.

17 Hastie ND, Allshire RC. Human telomeres: fusion and interstitial sites. Trends Genet 1989;5:326-31.
18 Maraschio P, Peretti D, Lambiase S, et al. A new chromosome instability disorder. Clin Genet 1986;30:353-65.

19 Sandberg AA. The chromosomes in human cancer and leukemia. Vol II. Amsterdam: Elsevier, 1990.

20 Pezzolo A, Gimelli G, Cohen A, et al. Presence of telomeric and subtelomeric sequences at the fusion points of ring chromosomes indicates that the ring syndrome is caused by ring instability. Hum Genet 1993;92:23-7.

21 Reeve A, Norman A, Sinclair P, Hamey Y, WhittingtonSmith R, Read A. A true telomeric translocation in a baby with Prader-Willi phenotype. F Med Genet 1992;29:205A.

22 Kuwano A, Mutirangura A, Dittrich B, et al. Molecular dissection of the Prader-Willi/Angelman syndrome region (15q11-13) by YAC cloning and FISH analysis. Hum Mol Genet 1992;1:417-25.

23 Aurias A, Dutrillaux B. A possible new type of chromosome rearrangement: telomere-centromere translocation (tct) followed by double duplication. Hum Genet 1986;72:25-6.

24 Willard HF. Centromeres-primary constrictions are primarily complicated. Hum Mol Genet 1992;1:667-8.

25 Yu GL, Blackburn EH. Developmentally programmed healing of chromosomes by telomerase in Tetrahymena. Cell 1991;67:823-32.

26 Müller F, Wicky C, Spicher A, Tobler H. New telomere formation after developmentally regulated chromosomal breakage during the process of chromatin diminution in Ascaris lumbricoides. Cell 1991;67:815-22.

27 Morin GB. Recognition of a chromosome truncation site associated with $\alpha$-thalassemia by human telomerase. Nature 1991;353:454-6.

28 Lamb J, Harris PC, Wilkie AOM, Wood WG, Dauwerse G Higgs DR. De novo truncation of chromosome $16 \mathrm{p}$ and healing with (TTAGGG) $n$ in the $\alpha$-thalassemia/mental retardation syndrome (ATR-16). Am $₹$ Hum Genet retardation syndro

29 Drets ME, Therman E. Human telomeric 6;19 translocation chromosome with a tendency to break at the fusion point. Chromosoma 1983;88:139-44.

30 Robinson WP, Bottani A, Yagang X, et al. Molecular cytogenetic, and clinical investigations of Prader-Willi syndrome patients. Am f Hum Genet 1991;49:1219-34.

31 Spence JE, Perciaccante RG, Greig GM, et al Uniparenta disomy as a mechanism for human genetic disease. $A m \mathcal{F}$ Hum Genet 1988;42:217-26.

32 Voss R, Ben-Simon E, Avital A, et al. Isodisomy of chromosome 7 in a patient with cystic fibrosis: could uniparental disomy be common in humans? Am $\mathcal{f}$ Hum Genet 1989;45:373-80

33 Temple K, Cockwell A, Hassold T, Pettay D, Jacobs P. Maternal uniparental disomy for chromosome 14. f Med Genet 1991:28:511-14.

34 Wang JCC, Passage MB, Yen PH, Shapiro LJ, Mohandas TK. Uniparental heterodisomy for chromosome 14 in a phenotypically abnormal familial balanced 13/14 Robertsonian translocation carrier. Am 7 Hum Genet 1991;48:1069-74.

35 Cattanach BM. Parental origin effects in mice. $\mathcal{F}$ Embryol Exp Morphol 1986;97(suppl):137-50. 